\title{
The Impact of Life Satisfaction on Chronological Age, Cognitive Age and Ideal Age
}

\author{
Avichai Shuv-Ami \\ College of Management, Rishon Lezion, Israel
}

\begin{abstract}
Using a sample of 655 individuals from 15-year olds to 79-year olds, the present research found that teenagers want to be older than their age and older people above 20-24 want to be younger than their age. Furthermore, life satisfaction has a major impact on the age people want to be in crises years, before the age of 40, 50, 60 and 70. Those with high life satisfaction more than those with low life satisfaction tend to have a more realistic ideal age, that is, closer to their actual age.
\end{abstract}

Keywords: age, life satisfaction on chronological age, cognitive age, ideal age

\section{Literature Review}

One of the first and most important segmenting variables is age. Products, advertising and the whole marketing-mix is built and changed to cater to segments of the market by age. But, consumers may not engage in purchasing behavior with accordance to the age written in their birth certificate (chronological age), but, they may behave according to the age they feel they are (cognitive or perceived age) or the age they would prefer to be (ideal age).

Most research in marketing concerning the relationship between chronological, cognitive and ideal age have dealt with the elderly (Barak \& Schiffman, 1981; Barak, Stern, \& Gould, 1988; Stephens, 1991; Wilkes, 1992; and others). Research on the relationship between life satisfaction or quality of life with age variables also dealt with the elderly (Cooper \& Miaoulis, 1988; Sherman, Schiffman, \& Dillon, 1988; Sherman \& Schiffman, 1991; and others).

The present research examines the relationship between life satisfaction and the age variable of those between the ages of 15 to 80. Research has found that life satisfaction is not related to chronological age (Lieberman, 1970; Sherman, Schiffman, \& Dillon, 1988). However, Sherman, Schiffman and Dillon (1988) found that life satisfaction is significantly related to cognitive age of the elderly. That is, the younger they perceive themselves the more satisfied they are with their lives. On the other hand, adults over the age of 30 tend to perceive their age as lower than their chronological age, and their ideal age even lower than their perceived or cognitive age (Barak, Stern, \& Gould, 1988; Lepisto, 1989). Below the age of 30, Lepisto (1989) found that the cognitive age and ideal age tend to be above the chronological age. These studies found that all age variables are correlated.

\section{Hypotheses}

It seems logical to assume that those with high life satisfaction have their cognitive age and ideal age closer

Avichai Shuv-Ami, Ph.D., Chairman of the Marketing and Advertising Department, Director of the IAA's (International Advertising Association) programs, Business School, College of Management. 
to their chronological age than those with low life satisfaction.

Or, in other words, the present study hypothesizes that:

H1: For those below the age of 30, cognitive age will be higher than chronological age, and ideal age will be higher than cognitive age.

H2: Those with high life satisfaction will have higher cognitive age and ideal age than those with low life satisfaction.

\section{Methodology}

A sample of 655 subjects was selected in quota sampling from different socio-economic areas in the Greater Tel Aviv Area. Face to face interviews were conducted. Thirteen groups from the age 15 years old to 79 , each was selected with at least 30 subjects in each group, half male and half female.

Four variables are used in this study: chronological age, cognitive age, ideal age and life satisfaction.

Chronological age was measured as an exact age. Barak and Schiffman's (1988) scale of cognitive age is used. The scale consists of four items: feel age, look age, interests age and do age. Ideal age is measured here based on Barak, Stern and Gould's (1988, p. 152), single-item question: "If you could be any age, what age would you most like to be?”

Life satisfaction is measured using Lumpkin and Hunt’s (1989) three-item scale.

\section{Results}

As hypothesized, Figure 1 shows that from 20-24 years old cognitive age is lower than chronological age, and ideal age is lower than cognitive age. Below the age of 20-24 these relationships are reversed; cognitive age and ideal age are higher than chronological age. Using $T$-test analysis, Table 1 indicates that most of these relationships are significant as hypothesized, but, the differences between cognitive age and ideal age in three age groups exist. In the teenager group one can expect small differences between the age types because their small number of years in life-how far can their ideal age be and their cognitive age. The insignificant results are in the other two groups (55-59, 65-69) may be due to a randomized occurrence resulting from the sample size or may be an explanation that this study cannot provide.

While most of the results in Figure 1 and Table 1 support Lepisto's (1989) finding the age group where those relationships are reversed is different. In Lepisto's (1989) study that was done in the U.S. the relationships were reversed the group age of 25-29 and in this current study, done in Israel, the relationships were reversed in the group age of 20-24. This difference may be explained by the fact that young adults in Israel become more mature at an earlier age than American young adults, due to army service that most Israeli's attend.

The present research found no difference in cognitive age between groups of high and low life satisfaction. Also, using $T$-test analysis, Figure 2 and Table 2 show partial support for the second hypotheses. In only four out of the 13 groups, there is a significant difference of ideal age between high and low life satisfaction. Those four groups' age: 35-39, 45-49, 55-59, and 64-69, have two interesting characteristics in common. First, they are old enough to have the ability to have a retrospective view on life and second, they are before a crisis year of changing their age category level from 30's to 40's, to 50's etc.. The other groups, other than those that life satisfaction affects their ideal age, are probably too young or too old to evaluate life in retrospect and into their future. 


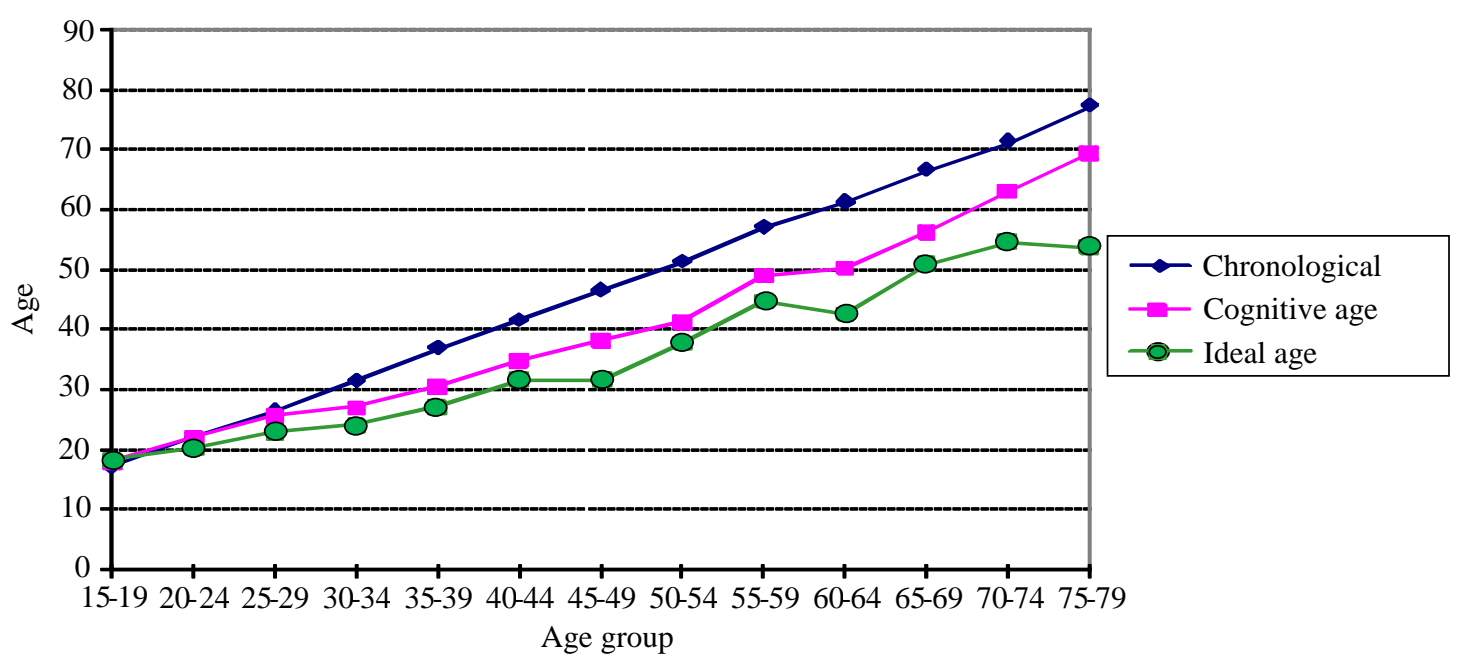

Figure 1. Differences between chronological age, cognitive age and ideal age.

Table 1

Differences Between Chronological Age, Cognitive Age and Ideal Age

\begin{tabular}{lllllllllllllll}
\hline \multicolumn{1}{l}{ Chron. age P } & D.f. & T-value Ideal age & P & D.f. & $T$-value & Cog. age & P & D.f. & T-value & Chron. age & Age group \\
\hline 17.2 & 0.002 & 98 & 3.21 & 18.3 & 0.468 & 95 & 0.73 & 18.0 & 0.000 & 95 & -5.76 & 17.2 & $15-19$ \\
22.1 & 0.060 & 73 & -2.83 & 20.3 & 0.100 & 71 & -2.64 & 22.0 & 0.832 & 71 & 0.21 & 22.1 & $20-24$ \\
26.5 & 0.000 & 58 & -6.31 & 23.0 & 0.000 & 54 & -4.04 & 25.6 & 0.030 & 56 & 3.09 & 26.5 & $25-29$ \\
31.5 & 0.000 & 60 & -8.12 & 24.1 & 0.010 & 57 & -3.69 & 27.1 & 0.000 & 57 & 7.27 & 31.5 & $30-34$ \\
37.0 & 0.000 & 54 & -9.94 & 27.1 & 0.005 & 47 & -2.96 & 30.5 & 0.000 & 47 & 10.40 & 37.0 & $35-39$ \\
41.7 & 0.000 & 55 & -9.13 & 31.7 & 0.011 & 51 & -2.63 & 34.8 & 0.000 & 52 & 8.55 & 41.7 & $40-44$ \\
46.6 & 0.000 & 52 & -9.91 & 31.7 & 0.000 & 49 & -4.22 & 38.2 & 0.000 & 50 & 11.20 & 46.6 & $45-49$ \\
51.4 & 0.000 & 36 & -7.40 & 37.7 & 0.051 & 35 & -2.02 & 41.4 & 0.000 & 35 & 10.11 & 51.4 & $50-54$ \\
57.1 & 0.000 & 21 & -4.87 & 44.7 & 0.910 & 20 & -1.78 & 49.1 & 0.000 & 20 & 6.81 & 57.1 & $55-59$ \\
61.3 & 0.000 & 34 & -8.21 & 42.6 & 0.000 & 34 & -4.00 & 50.3 & 0.000 & 34 & 8.83 & 61.3 & $60-64$ \\
66.7 & 0.000 & 23 & -4.62 & 51.0 & 0.205 & 23 & -1.30 & 56.2 & 0.000 & 23 & 4.55 & 66.7 & $65-69$ \\
71.4 & 0.000 & 32 & -6.20 & 54.7 & 0.001 & 31 & -3.54 & 63.2 & 0.000 & 31 & 6.43 & 71.4 & $70-74$ \\
77.4 & 0.000 & 25 & -5.34 & 53.7 & 0.020 & 24 & -3.44 & 69.5 & 0.000 & 24 & 4.62 & 77.4 & $75-79$ \\
\hline
\end{tabular}

\section{Discussion}

Cognitive age and ideal age are more important than chronological age to advertisers of age sensitive product or services, such as, cosmetics for teenagers or homes for the elderly etc.. Advertisers ask what should be the positioning or what age should those appearing in the advertisement be, etc.. This study, like previous ones, shows that in most cases, there is a difference between chronological age and cognitive and ideal age. Teenagers want to be older than their age and older people above 20-24 want to be younger than their age. Thus, the positioning, the images used in the advertisement and its layout or atmosphere should agree with the age people want to be and not the age that they actually are.

Furthermore, life satisfaction has a major impact on the age people want to be in crises years, before the age of either 40, 50, 60 and 70. Thus, in societies or segments where the satisfaction of life tends to be high, the ideal age is lower than those with low life satisfaction. The present research provides in Table 1 and Table 2 the exact age difference found here, but they may be culturally biased. Thus, more research should be done in different cultures and segments, examining the differences found here, before one uses these numbers. 


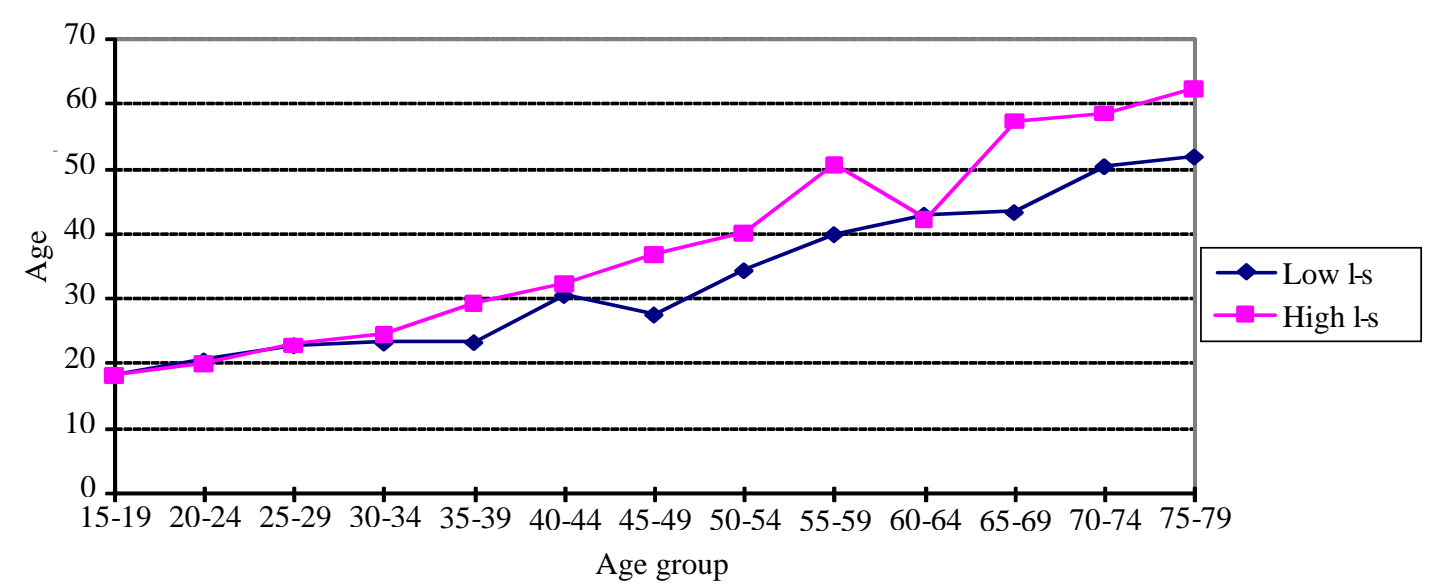

Figure 2. Differences of ideal age between high and low life satisfaction.

Table 2

Differences of Ideal Age Between High and Low Life Satisfaction

\begin{tabular}{|c|c|c|c|c|c|c|}
\hline \multirow{2}{*}{$\mathrm{P}$} & \multirow{2}{*}{$T$-value } & \multirow{2}{*}{ D.f. } & \multirow{2}{*}{$\begin{array}{l}\text { Average ideal } \\
\text { High l-s }\end{array}$} & \multirow{2}{*}{$\begin{array}{l}\text { Age } \\
\text { Low l-s }\end{array}$} & \multirow{2}{*}{ - Chronological age } & \multirow{2}{*}{ Age group } \\
\hline & & & & & & \\
\hline 0.964 & -0.05 & 96 & 18.3 & 18.3 & 17.2 & $15-19$ \\
\hline 0.747 & 0.32 & 72 & 20.2 & 20.6 & 22.1 & $20-24$ \\
\hline 0.914 & -0.1 & 56 & 23 & 22.9 & 26.5 & $25-29$ \\
\hline 0.432 & -0.77 & 59 & 24.7 & 23.3 & 31.5 & $30-34$ \\
\hline 0.001 & -3.09 & 53 & 29.4 & 23.4 & 37.0 & $35-39$ \\
\hline 0.491 & -0.69 & 54 & 32.3 & 30.6 & 41.7 & $40-44$ \\
\hline 0.001 & -3.46 & 51 & 36.9 & 27.6 & 46.6 & $45-49$ \\
\hline 0.129 & -1.56 & 35 & 40.1 & 34.4 & 51.4 & $50-54$ \\
\hline 0.027 & -2.39 & 20 & 50.7 & 39.9 & 57.2 & $55-59$ \\
\hline 0.884 & 0.15 & 33 & 42.2 & 42.9 & 61.3 & $60-64$ \\
\hline 0.042 & -2.17 & 21 & 57.3 & 43.3 & 66.6 & $65-69$ \\
\hline 0.139 & -1.52 & 29 & 58.5 & 50.3 & 71.4 & $70-74$ \\
\hline 0.318 & -1.02 & 24 & 62.3 & 51.8 & 77.5 & $75-79$ \\
\hline
\end{tabular}

\section{References}

Benny, B., \& Leon, G. S. (1981). Cognitive age: A nonchronological age variable. In B. M. Kent (Ed.), Advances in Consumer Research 8. Ann Arbor, MI: Association for Consumer Research, 602-606.

Benny, B., Barbara, S., \& Stephen, J. G. (1988). Ideal age concepts: An exploration. Consumer Research, 15, 146-152.

Cooper, D. P., \& Miaoulis, G. (1988). Altering corporate strategic Criteria to reflect the changing environment: The role of life satisfaction and the growing senior market. California Management Review, Fall, 87-97.

Lawrece, R. L. (1989). The effect of cognitive age and sex on consumer well-being. Conference on the Elderly Consumer. University of Florida.

Lieberman, L. R. (1970). Life satisfaction in young and the old. Psychological Report, 27, 75-79.

Lumpkin, F. J., \& Hunt, B. J. (1989). Mobility as influence on retail patronage behavior of the elderly: Testing conventional wisdom. Journal of Academy of Science, 17(Winter), 1-12.

Sherman, E., \& Schiffman, L. G. (1991). Quality-of-life (QOL) assessment of older consumers: A Retrospective Review. Journal of Business and Psychology, Fall, 107-119.

Sherman, E., Schiffman, L. G., \& Dillon, W. R. (1988). Agelgender segments and quality of life differences. In S. Shapiro, \& A. H. Walle (Eds.), Winter Educators' Conference. Chicago: American Marketing Association, 319-320.

Stephens, N. (1991). Cognitive age: A useful concept for advertising? Journal of Advertising, XX(4), 37-48.

Wilkes, R. E. (1992). A structural modeling approach to the measurement and meaning of cognitive age. Journal of Consumer Research, September, 292-301. 